\title{
Lung and Eye Disease Develop Concurrently in Supplemental Oxygen-Exposed Neonatal Mice
}

Lakshanie C. Wickramasinghe, ${ }^{*}$ Maverick Lau, ${ }^{* \dagger}$ Devy Deliyanti, ${ }^{\ddagger}$ Timothy A. Gottschalk, ${ }^{*}$ Peter van Wijngaarden, ${ }^{\S \uparrow}$ Dean Talia, Chad Johnson, Jennifer L. Wilkinson-Berka, Evelyn Tsantikos, ${ }^{*}$ and Margaret L. Hibbs*

From the Leukocyte Signalling Laboratory, ${ }^{*}$ Department of Immunology and Pathology, Central Clinical School, the Department of Diabetes, ${ }^{\ddagger}$ and the Monash Micro Imaging, Alfred Research Alliance," Monash University, Melbourne, Victoria; the Lung Health Research Centre, ${ }^{\dagger}$ Department of Pharmacology and Therapeutics, and the Department of Surgery-Ophthalmology, ${ }^{\S}$ University of Melbourne, Victoria; and the Centre for Eye Research Australia, "Royal Victorian Eye and Ear Hospital, East Melbourne, Australia

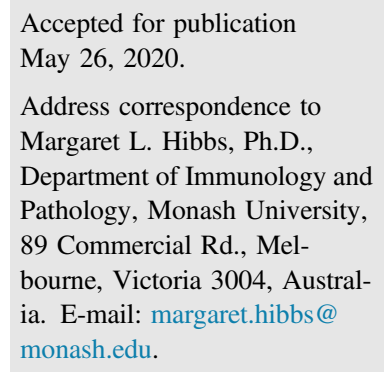

\begin{abstract}
Bronchopulmonary dysplasia (BPD) and retinopathy of prematurity (ROP) are two debilitating disorders that develop in preterm infants exposed to supplemental oxygen to prevent respiratory failure. Both can lead to lifelong disabilities, such as chronic obstructive pulmonary disease and vision loss. Due to the lack of a standard experimental model of coincident disease, the underlying associations between BPD and ROP are not well characterized. To address this gap, we used the robust mouse model of oxygen-induced retinopathy exposing $\mathrm{C} 57 \mathrm{BL} / 6$ mice to $75 \%$ oxygen from postnatal day 7 to 12 . The cardinal features of ROP were replicated by this strategy, and the lungs of the same mice were simultaneously examined for evidence of BPD-like lung injury, investigating both the short- and long-term effects of early-life supplemental oxygen exposure. At postnatal days 12 and 18, mild lung disease was evident by histopathologic analysis together with the expected vasculopathy in the inner retina. At later time points, the lung lesion had progressed to severe airspace enlargement and alveolar simplification, with concurrent thinning in the outer layer of the retina. In addition, critical angiogenic oxidative stress and inflammatory factors reported to be dysregulated in ROP were similarly impaired in the lungs. These data shed new light on the interconnectedness of these two neonatal disorders, holding potential for the discovery of novel targets to treat BPD and ROP. (Am J Pathol 2020, 190: 1801-1812; https://doi.org/10.1016/j.ajpath.2020.05.016)
\end{abstract}

Supplemental oxygen treatment is commonly used in neonatal intensive care units to promote the survival of atrisk premature infants unable to perform respiration independently. ${ }^{1}$ A major consequence of oxygen therapy is the development of a chronic lung disorder known as bronchopulmonary dysplasia (BPD), affecting approximately $50 \%$ of newborns with birth weights $<1000 \mathrm{~g}$. ${ }^{2}$ BPD encompasses the parenchyma of the lungs and is characterized by alveolar simplification and enlargement, as a result of interrupted secondary septation and abnormal vascular organization. ${ }^{3}$ By adulthood, pulmonary complications often worsen, progressing to chronic obstructive pulmonary disease. ${ }^{4}$ In a proportion of preterm infants, supplemental oxygen therapy can also cause retinopathy of prematurity (ROP), a leading cause of long-term vision impairment and blindness. ${ }^{5}$ Exposure to hyperoxia disrupts normal retinal blood vessel development. ${ }^{6}$ Independent studies by several groups have reported the comorbid presentation of ROP and BPD in premature neonates receiving oxygen supplementation, ${ }^{7-10}$ with $71.5 \%$ of these infants affected by both diseases simultaneously. ${ }^{11}$ Although both disorders share similar initiating factors and are often comorbid, they are seldom studied concurrently.

An experimental model of ROP, known as the oxygeninduced retinopathy (OIR) model, is widely used in neonatal retinal research because it recapitulates the biphasic pathological features seen in human infants. ${ }^{12}$ In this model, mice

Supported by National Health and Medical Research Council grants APP1147267 (M.L.H.) and APP1141208 (E.T. and M.L.H.) and an Australia Government Research Training Program scholarship administered by Monash University (L.C.W.).

Disclosures: None declared.

Current address of D.D. and J.L.B., Department of Anatomy and Neuroscience, University of Melbourne, Victoria, Australia. 
are exposed for 5 days to supplemental oxygen from postnatal day (PN) 7 to 12 before being returned to room air. ${ }^{6}$ With this scheme, mice develop retinal vaso-obliteration at PN12 and pathologic neovascularization at PN18 due to upregulation of vascular endothelial growth factor (Vegfa) in the retina. No such standard model is available to study BPD, and only two studies have examined lung and eye pathologic findings concurrently. In one study, rats were exposed to 95\% oxygen from PN4 to PN14 which resulted in reduced thickness of retinal layers and increased alveolar airspace diameter at PN28. ${ }^{13}$ In another study, newborn rats were exposed for 18 days to 24-hour alternating cycles of $80 \%$ to $21 \%$ oxygen; however, this protocol was not sufficient to induce histologic or functional changes in the lung, despite showing ROP-like pathologic findings in the eye. ${ }^{14}$ These studies did not examine shared disease mechanisms or assess multiple time points to characterize temporal disease progression.

In this study, we aimed to address these knowledge gaps by using the established experimental model of ROP to examine the effects of short-term, high-oxygen exposure on the developing lungs of mice. We found that 5 days of supplemental oxygen exposure leads to ROP, as expected, but also causes lung defects that are analogous to BPD in infants and progresses to emphysema in adults. We furthermore found the long-lasting consequence of supplemental oxygen on the developing retinal and choroidal vasculature. Pathways reported to be dysregulated in ROP, namely angiogenesis, oxidative stress, and inflammation, exhibited similar patterns of alteration in the lung, revealing a possible mechanistic link between the two disorders. This work may lead to the identification of therapeutic targets to concurrently manage both conditions.

\section{Materials and Methods}

\section{Experimental Animals}

Neonatal C57BL/6 mice in litter sizes of six to seven pups (to control for maternal nutrition) were exposed to $75 \%$ oxygen from PN7 to PN12, then returned to room air. ${ }^{15}$ Mothers and litters were cycled with $21 \%$ oxygen (room air) for 3 hours daily to reduce oxygen-induced toxic effects to the dam. ${ }^{16}$ Mice were analyzed on PN12, PN18, PN40, and PN80, with comparisons made with age-matched C57BL/6 mice exposed to room air. All experiments were performed in accordance with National Health and Medical Research Council of Australia guidelines for animal experimentation, with ethics approval granted from the Alfred Research Alliance Animal Ethics Committee (E1746-2017).

\section{Bronchoalveolar Lavage}

Mice were lethally anesthetized by intraperitoneal injection of sodium pentobarbitone $(600 \mathrm{mg} / \mathrm{kg}$; Sigma-Aldrich,
Castle Hill, NSW, Australia). Bronchoalveolar lavage (BAL) was performed by flushing lungs with $200 \mu \mathrm{L}$ (PN12 and PN18) and $400 \mu \mathrm{L}$ (PN40 and PN80) of phosphatebuffered saline (PBS), cell counts were measured with a hemocytometer to determine cell concentration normalized to $1 \mathrm{~mL}$, and cells were centrifuged onto glass slides (Shandon CytoSpin 3; Thermo Fisher Scientific, Waltham, MA) followed by staining with Diff-quik (Lab Aids, North Narrabeen, NSW, Australia).

\section{Lung Histologic and Morphometric Analysis}

Lungs were inflation-fixed in $10 \%$ formalin at $25-\mathrm{cm}$ water pressure and then fixed for 24 hours before paraffin embedding. Whole lung sections were cut (5- $\mu \mathrm{m}$ thickness), mounted onto SuperFrost slides, and stained with hematoxylin and eosin (H\&E). Photomicrographs of sections were captured on an Olympus BX-51 light microscope using $10 \times$ and $40 \times$ objectives (Olympus Australia, Notting Hill, VIC, Australia). The mean linear intercept (airspace diameter) was calculated as previously described. ${ }^{17,18}$ Briefly, four random images $(10 \times)$ were captured of each H\&E-stained lung-cross section, ten equally distributed lines were drawn on each. The number of times each line intercepted with an alveolar air wall was counted and averaged for each lung. Airspace diameter was then calculated by dividing the known length of the line drawn across the lung cross-sections (in $\mu \mathrm{m}$ ) by the mean number of alveolar wall intercepts. To determine the alveolar septal wall thickness, two random lung images $(10 \times)$ were uploaded onto ImageJ software version $1.37(\mathrm{NIH}$, Bethesda, MD; http://imagej.nih.gov/ij) and 60 horizontal lines were drawn perpendicular to randomly selected alveolar walls, per image. The mean thickness of the wall (in $\mu \mathrm{m}$ ) was averaged per lung sample, as previously described. ${ }^{19}$ The investigator (L.C.W.) was blinded to the experimental groups during both morphometric analyses.

\section{Lung Immunohistochemistry}

Heat-induced antigen retrieval was performed on deparaffinized lung sections with Dako Target Retrieval Solution (Dako Cytomation, Carpinteria, CA). Sections were blocked for 30 minutes with $5 \%$ bovine serum albumin and incubated with 1:500 biotinylated rabbit anti-3-nitrotyrosine (Millipore, Burlington, MA) in PBS $/ 0.2 \%$ bovine serum albumin for 3 hours at room temperature, followed by 1:200 horseradish peroxidase-conjugated secondary antibody for 1 hour. Color development was performed with 1:50 diaminobenzidine (DAB) chromogen solution (Agilent, Santa Clara, CA) and counterstained in hematoxylin. Negative and positive controls for 3-nitrotyrosine were generated at the same time. Two negative controls were prepared using retinal sections from an oxygen-exposed group without the addition of primary or secondary antibody, respectively. The same retinal tissue was stained in the equivalent way as the lung tissue and therefore 
acted as the positive control. Quantitation of DAB-positive staining was performed on four random images $(40 \times$ objective) of a single lung sample using a custom ImageJ script (Supplemental Table S1). In brief, the semiautomated script was written using the open source ImageJ software version $1.37^{20}$ (https://imagej.nih.gov/ij/download.html), to measure the percentage area of $\mathrm{DAB}$ staining in tissue for each image. A best-fit threshold of positive DAB-stained tissue was determined using a montage of ten randomly selected images. The same method was used to find a threshold for the total tissue area. These thresholds were used for analysis of all subsequent images for consistency. The script then used this to automatically calculate the percentage area of positive $\mathrm{DAB}$ tissue in each image.

\section{Eye Fixation and Retinal Immunofluorescence}

The retinas were dissected and wholemounted as described. ${ }^{16}$ Retinal wholemounts were fixed with $100 \%$ methanol at $-20^{\circ} \mathrm{C}$ for 10 minutes and incubated overnight at $4^{\circ} \mathrm{C}$ with the endothelial cell marker fluorescein isothiocyanate-conjugated isolectin B4 at 1:100 in PBS [Griffonia (Bandeiraea) simplicifolia Isolectin-B4; Sigma-Aldrich]. The retinas were washed with PBS and mounted with Dako Cytomation fluorescent mounting medium. Epifluorescence microscopy was performed (Zeiss Axio Observer X1; Zeuss, Oberkochen, Germany) and images were captured with a $10 \times$ objective.

\section{Choroid Diameter Measurements}

Paraffin-embedded eyes were serially sectioned $(3-\mu \mathrm{m}$ thickness), and every 20th section was stained with H\&E. Twelve photomicrographs $(40 \times)$ of each cross-section were captured across the full circumference of the eye. With the use of ImageJ software, the 60 shortest straight lines perpendicular to the choroid were drawn at $5-\mu \mathrm{m}$ intervals apart per image, from the top of the choroid (sclera/choroid boundary) to the bottom (pink lamina vitrea). The mean diameter (in $\mu \mathrm{m}$ ) per section for each eye was determined to obtain choroidal thickness. The investigator (L.C.W.) was blinded to experimental groups.

\section{RNA Isolation and Quantitative Real-Time PCR}

RNA was extracted using the RNeasy Kit (Qiagen Pty. Ltd., Chadstone, VIC, Australia) from whole lungs and converted to cDNA using a high-capacity RNA to cDNA kit (Life Technologies, Carlsbad, CA). Quantitative real-time PCR was undertaken as previously described, ${ }^{21}$ with the following genes of interest: Vegfa, Vegfr2, Pdgfra, Pdgfrb, Pdgfa, Pdgfb, Tgfbl, Tgfbr2, Ctgf (Ccn2), Noxl, Nox2 (Cybb), Nox4, Hmoxl, Nqo1, Illb, Tnfa (Tnf), Il6, and Cxcll5 (Table 1). These genes were evaluated using prevalidated Taqman assays (Life Technologies).

\section{Statistical Analysis}

Statistical analyses were undertaken using the nonparametric $U$-test in GraphPad Prism software version 4.03 (GraphPad Software Inc., San Diego, CA). $P<0.05$ was considered statistically significant.

\section{Results}

\section{Supplemental 0xygen Disrupts Normal Vascular Development of the Retina and Choroid}

To examine the simultaneous effect of supplemental oxygen on the eyes and lungs of mice, C57BL/6 mice were exposed to $75 \%$ oxygen for 5 days from PN7 to PN12, which led to

Table 1 Real-Time PCR Taqman Mouse Primers

\begin{tabular}{|c|c|c|}
\hline Gene symbol & Gene name & TaqMan Primer Assay ID \\
\hline Vegfa & Vascular endothelial growth factor A & Mm00437306_m1 \\
\hline Vegfr2 $(K d r)$ & Vascular endothelial growth factor receptor 2 & Mm00440112_g1 \\
\hline Pdgfa & Platelet-derived growth factor $\alpha$ & Mm01205760_m1 \\
\hline Pdgfra & Platelet-derived growth factor receptor $\alpha$ & Mm00440701_m1 \\
\hline Pdgfb & Platelet-derived growth factor $\beta$ & Mm00440677_m1 \\
\hline Pdgfrb & Platelet-derived growth factor receptor $\beta$ & Mm00435553_m1 \\
\hline $\operatorname{Ctgf}(\operatorname{Ccn} 2)$ & Connective tissue growth factor & Mm01192933_g1 \\
\hline Nox1 & NADPH oxidase 1 & Mm00549170_m1 \\
\hline Nox2 (Cybb) & NADPH oxidase 2 & Mm01287743_m1 \\
\hline Nox4 & NADPH oxidase 4 & Mm00479246_m1 \\
\hline Hmox1 & Heme oxygenase 1 & Mm00516005_m1 \\
\hline Nqo1 & NADPH dehydrogenase quinone & Mm01253561_m1 \\
\hline Cxcl15 & CXCL15 & Mm00441263_m1 \\
\hline Gapdh & Glyceraldehyde-3-phosphate dehydrogenase & Mm99999915_g1 \\
\hline
\end{tabular}


the expected reduction in body weight gain at PN12 and PN18. By PN40 and PN80, body weights had normalized (Supplemental Figure S1). Retinal wholemounts revealed marked vaso-obliteration at PN12 in the central retina of all mice exposed to supplemental oxygen (Figure 1A). Similarly, abnormal neovascularization was observed in the midperipheral to peripheral region of the retina of all mice in the supplemental oxygen group at PN18 but not in room air controls (Figure 1B), confirming the development of the hallmark clinical features of human ROP. H\&E-stained cross-sections of eyes from oxygen-exposed mice at PN40 and PN80 demonstrated thinning of the choroid compared with room air controls (Figure 1, C and D), confirmed by choroid diameter quantitation (Figure 1E).

\section{Supplemental 0xygen Acutely Impairs Normal Alveolarization in the Lung}

We next evaluated H\&E-stained cross-sections of inflation-fixed lungs of the same mice at PN12 and PN18, which revealed significantly thickened alveolar walls in mice exposed to supplemental oxygen compared with age-matched room air-exposed controls (Figure 2, A-C). However, no significant differences in alveolar diameter between the two groups at PN12 and PN18 were observed (Figure 2D).

\section{Supplemental 0xygen Acutely Dysregulates Vascular and Alveolar Growth Factors in the Lung}

VEGF-A is critical for the development of the retinal vasculature, and its expression is down-regulated at PN12 in the OIR model. ${ }^{22}$ Indeed, the biphasic expression of $V e g f a$ in the retina is responsible for the initial vasoobliteration and rebounding neovascularization that are observed in the OIR model. ${ }^{22-24}$ Like in the retina, a marked reduction of Vegfa mRNA expression was observed in the lungs of oxygen-exposed mice at PN12, which was up-regulated by PN18 (Figure 3A). Expression of the corresponding receptor, Vegfr2 $(K d r)$, showed minimal differences at PN12 between supplemental oxygen and room air control groups, but at PN18, its expression was significantly increased (Figure 3B). This finding indicates that the VEGF signaling axis is affected by supplemental oxygen during alveologenesis, contributing to impaired vascular growth in the lungs.

We next investigated how the genes encoding plateletderived growth factor (PDGF)-A, PDGF-B, and their receptors, PDGFR- $\alpha$ and PDGFR- $\beta$, recognized as key regulators of alveolar structural development and commonly abrogated in infants with BPD, ${ }^{25-27}$ were affected by supplemental oxygen exposure in the OIR model. At PN12, supplemental oxygen induced a significant reduction in gene expression of $P d g f a$, which was largely restored to room air control levels by PN18 (Figure 3C). Pdgfb levels were strongly reduced at PN12 by supplemental oxygen, and
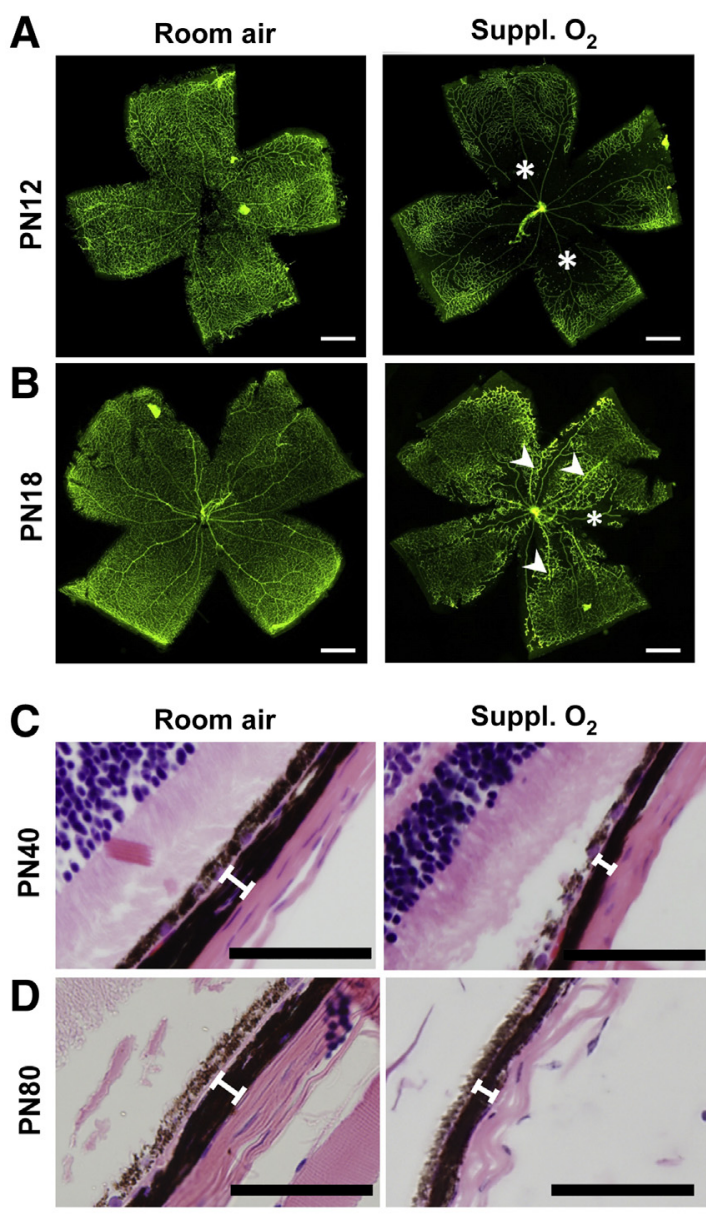

Suppl. $\mathrm{O}_{2}$

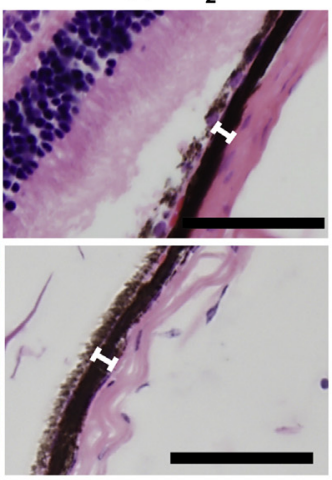

E

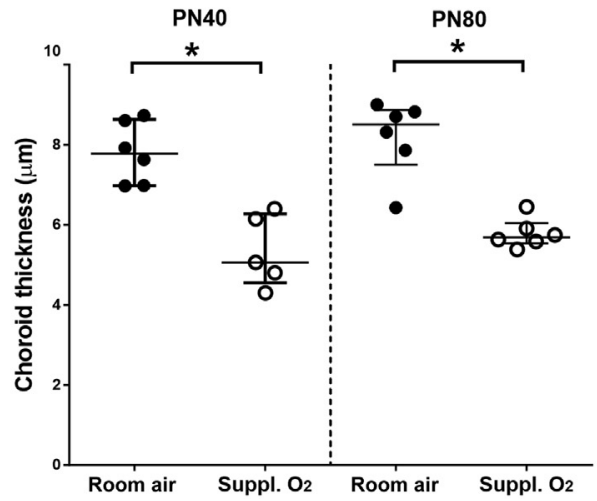

Figure 1 Vascular degeneration in the inner and outer retina of neonatal mice exposed to supplemental oxygen. A and B: Representative retinal wholemounts immunolabeled with fluorescein isothiocyanate-conjugated isolectin to show the retinal vasculature (green) of $\mathrm{C} 57 \mathrm{BL} / 6$ mice exposed to room air and supplemental oxygen (Suppl. $0_{2}$ ) analyzed at postnatal day (PN) 12 (A) and PN18 (B). Vasoobliteration at PN12 is marked by asterisks, and at PN18, neovascularization is indicated with arrowheads in the retinal midperiphery, with persistent vaso-obliteration in the central retina. C and D: Representative hematoxylin and eosin-stained photomicrographs of choroid (brackets) analyzed at PN40 (C) and PN80 (D). E: Quantitation of choroidal thickness of eye sections shown in $\mathbf{C}$ and $\mathbf{D}$. The retinas were obtained from the same mice used to assess lung pathologic features in subsequent figures. Data are expressed as medians \pm interquartile ranges. $n=5$ to 6 mice per group. Statistical significance was determined with a nonparametric, $U$-test (2-tailed). ${ }^{*} P<0.05$. Scale bars: $500 \mu \mathrm{m}$ (A and B); $50 \mu \mathrm{m}$ $(\mathbf{C}$ and $\mathbf{D})$. Original magnification: $\times 10(\mathbf{A}$ and $\mathbf{B}) ; \times 40(\mathbf{C}$ and $\mathbf{D})$. 
although some restoration in expression was evident, levels remained significantly lower than room air controls at PN18 (Figure 3D). When the receptors were examined, a significant reduction in Pdgfra expression in the lungs was observed only at PN18 but not at PN12 (Figure 3E). Similarly, supplemental oxygen did not affect $P d g f r b$ expression in the lung at PN12; however, its expression was significantly reduced at PN18 (Figure 3F). Alterations in these factors in response to supplemental oxygen are consistent with the stereologic deformities observed in the lungs of mice after oxygen exposure.

Changes in the genes encoding transforming growth factor (TGF)- $\beta 1$ (Tgfb1), TGF- $\beta$ receptor 2 (Tgfbr2), and connective tissue growth factor (CTGF) (Ctgf, also known as $C c n 2$ ) were also assessed to determine the effect of oxygen on the developing extracellular matrix but no changes in expression of any of these genes at PN12 or PN18 was observed (Figures 3, G-I).

\section{Supplemental 0xygen Chronically Impairs Normal Alveolarization in the Lung}

To examine whether supplemental oxygen exposure in early life resulted in long-term lung damage, the lungs of mice at PN40 and PN80 were evaluated. Alveolar enlargement and simplification were observed at PN40 and PN80 (Figure 4, A and B). When quantitated, a mild but significant increase in airspace diameter was apparent at PN40, which had progressed by PN80 (Figure 4C).

\section{Supplemental 0xygen Induces Protein Peroxidation in the Lung Parenchyma}

Given the key involvement of hyperoxia-induced reactive oxygen species (ROS) and reactive nitrogen species (RNS) production in ROP and BPD, ${ }^{16,28,29}$ the oxidative stress-induced damage in the lungs was assessed. At PN12, 3-nitrotyrosine staining was strongly detected in alveolar walls and alveolar macrophages of oxygenexposed mice compared with room air controls (Figure 5, A and B). Minimal differences were observed at PN18 (Figure 5, A and B), PN40, or PN80 (Figure 5, $\mathrm{A}$ and $\mathrm{C}$ ), indicating that ROS and RNS had dissipated at these later time points. Gene expression of Noxl and Nox2 $(C y b b)$ was up-regulated at PN12 in the lungs of supplemental oxygen-exposed mice, but only Nox2 $(C y b b)$ mRNA remained elevated at PN18; no difference was observed in Nox4 mRNA expression at either time point (Figure 5, D-F). Gene expression of the cytoprotective enzyme NADPH dehydrogenase quinone 1 ( Nqol) was elevated at PN12 (Figure 5G), whereas no change in heme oxygenase-1 (Hmoxl) was observed (data not shown), suggesting that NQO1 is the main antioxidant that is mobilized after the oxygen insult.

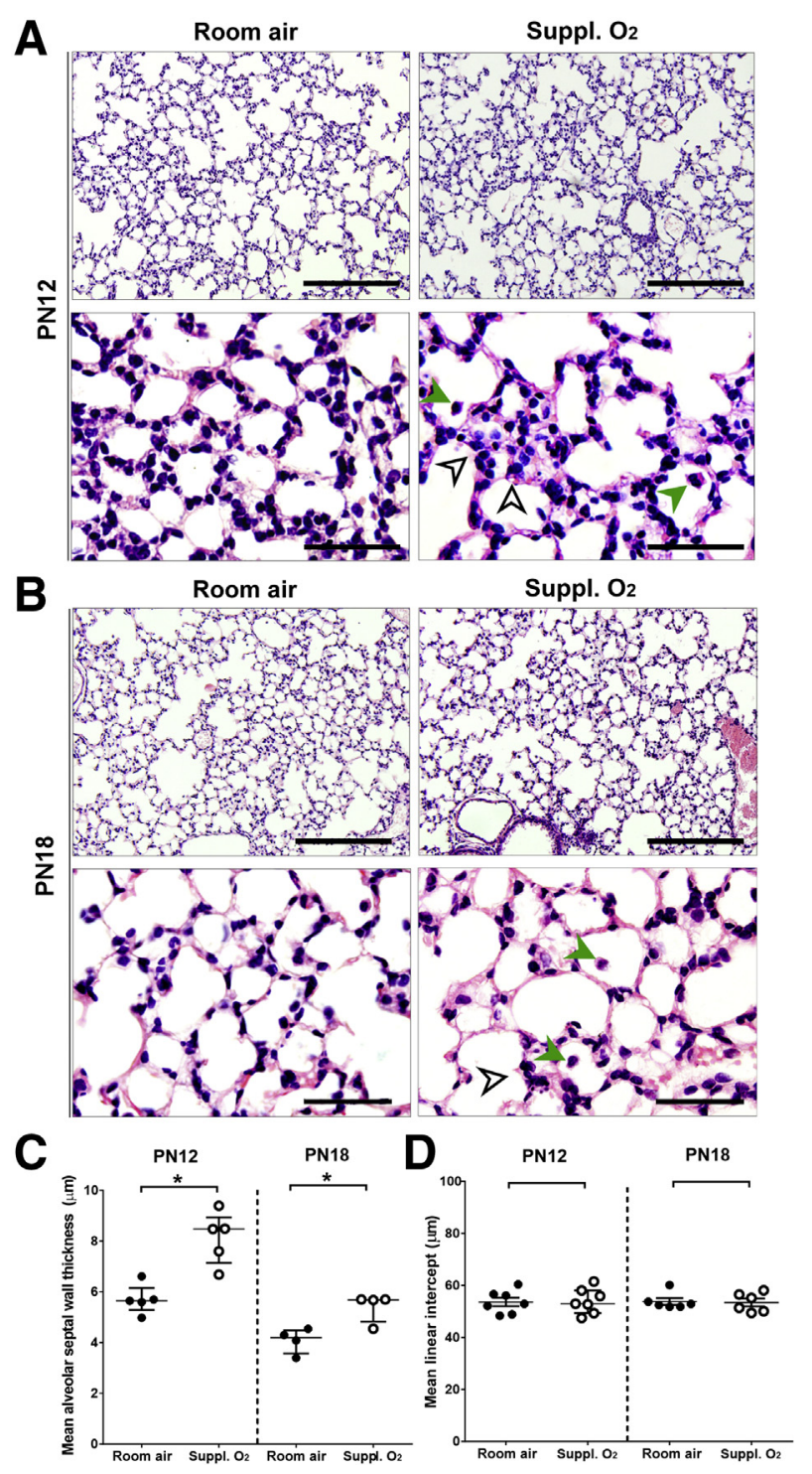

Figure 2 Alveolar wall thickening at postnatal day (PN) 12 and PN18 in neonates exposed to supplemental oxygen. $\mathbf{A}$ and $\mathbf{B}$ : Representative hematoxylin and eosin-stained lung sections from $\mathrm{C} 57 \mathrm{BL} / 6$ mice housed in room air or exposed to $75 \%$ oxygen (Suppl. $0_{2}$ ) from PN7 to PN12 analyzed at PN12 (A) and PN18 (B), depicting distinct honeycomb-like alveolar saccules in room air control groups compared with diffuse regions of alveolar wall thickening (white arrowheads) and immune cells (green arrowheads) in supplemental oxygen groups. C and D: Quantitation of alveolar septal wall thickness (C) and alveolar airspace size (D) via mean linear intercept length of hematoxylin and eosin-stained lung tissue sections shown in panels $\mathbf{A}$ and $\mathbf{B}$. Data are expressed as medians \pm interquartile ranges. $n=4$ to 7 mice per group. Statistical significance was determined with a nonparametric $U$-test (2-tailed). ${ }^{*} P<0.05$. Scale bars: $200 \mu \mathrm{m}$ (A and $\mathbf{B}$, top rows); $50 \mu \mathrm{m}$ (A and $\mathbf{B}$, bottom rows). Original magnification: $\times 10$ (A and $B$, top rows); $\times 40$ (A and B, bottom rows).

\section{Supplemental 0xygen Induces Inflammation in Alveolar Airspaces}

Finally, the degree of lung inflammation was evaluated by examining BAL. Alveolar macrophages were the predominant cell type in the BAL of all mice regardless 

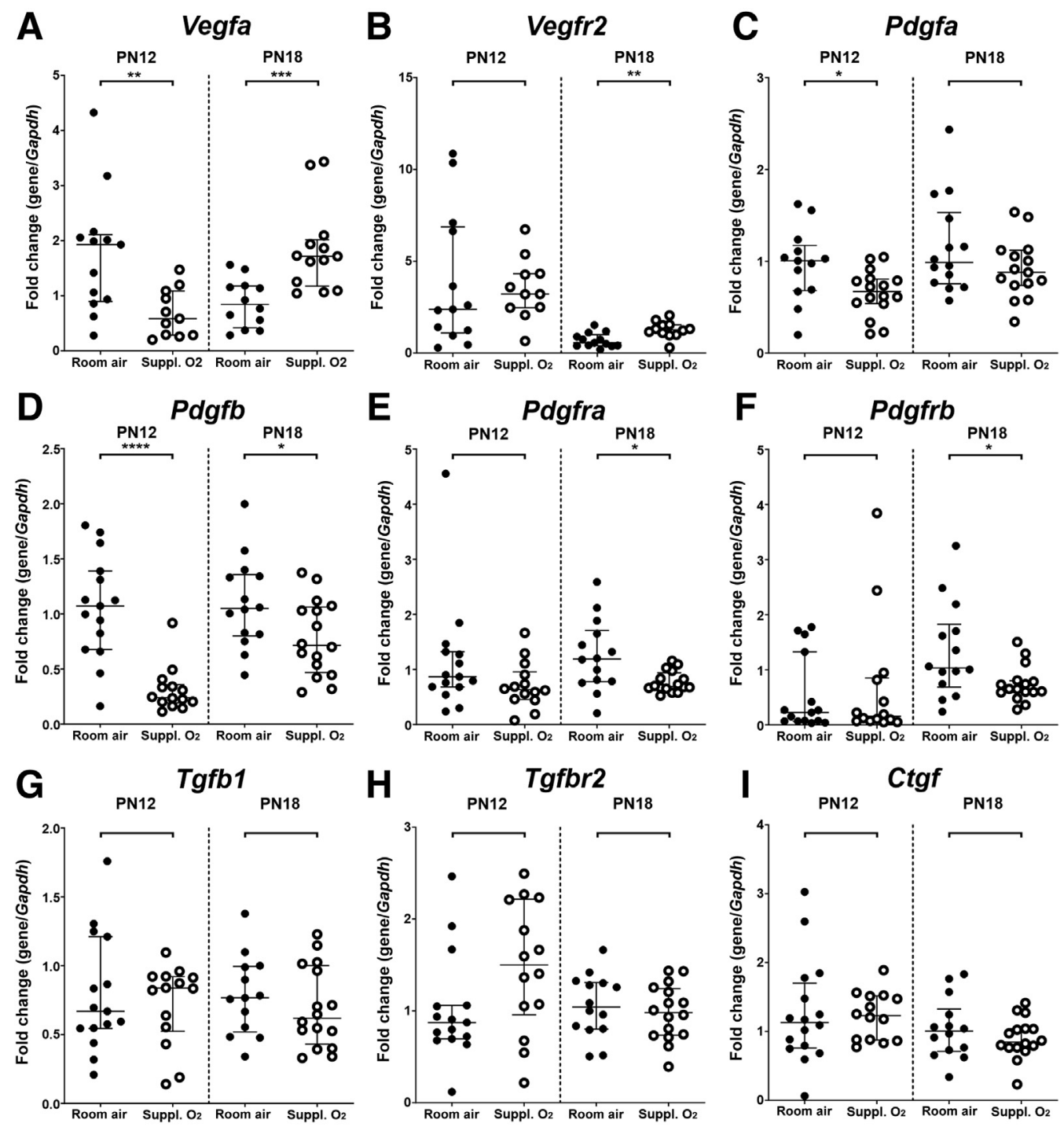

Figure 3 Impaired angiogenesis and developmental pathways in neonatal lung after supplemental oxygen exposure. Gene expression at postnatal day (PN) 12 or PN18 of Vegfa (A), Vegfr2 (Kdr) (B), Pdgfa (C), Pdgfb (D), Pdgfra (E), Pdgfrb (F), Tgfb1 (G), Tgfbr2 (H), and Ctgf (Ccn2) (I) by quantitative real-time PCR of lung tissue from $\mathrm{C} 57 \mathrm{BL} / 6$ mice housed in room air or exposed to supplemental oxygen (Suppl. $0_{2}$ ) from PN7 to PN12. Relative change was calculated using the $2^{-\Delta \Delta C T}$ method comparing supplemental oxygen-exposed mice with room air-exposed control mice. Mice used in this study were derived from four independent experimental runs, and the data presented are a compilation of two independent quantitative real-time PCR experiments. Data are presented as medians [relative change (gene/Gapdh)] \pm interquartile ranges. $n=11$ to 16 mice; $n=12$ to 13 mice $(\mathbf{A}$ and $\mathbf{B}) ; n=14$ to 16 mice (C-I), mean of triplicate measurements per mouse. Statistical significance was determined with a nonparametric $U$-test (2-tailed) with outliers removed using the Grubbs test. ${ }^{*} P<0.05,{ }^{* *} P<0.01,{ }^{* *} P<0.001$, and ${ }^{* * * * P}<0.0001$.

of treatment or time point examined (Figure 6A). However, the alveolar macrophages from the BAL of mice exposed to supplemental oxygen were enlarged and vacuolated and had pseudopodia projections, consistent with a state of activation. In contrast, those from agematched room air controls were smaller, indicative of a quiescent phenotype. In addition, neutrophils were present in the BAL of oxygen-exposed mice at PN12 (Figure 6A). The immune cell concentration in BAL was significantly increased at PN12 and PN18 (Figure 6B) and to a lesser extent at PN40 (Figure 6C) in the supplemental oxygen-exposed groups compared with age-matched room air controls, indicating persistent inflammation, which was attenuated at PN80 (Figure 6C). Whole lung tissue gene expression analysis of proinflammatory cytokines and chemokines revealed elevated mRNA levels of $I l l b$, Tnfa (Tnf), and Cxcll5 at PN12 in the supplemental oxygen-exposed groups compared with room air controls, with elevated Tnfa (Tnf) and Cxcl15 mRNA levels sustained at PN18 (Figure 6, D-F). Interestingly, the expression of Il6 mRNA was unchanged across both time points (Figure 6G). 
A

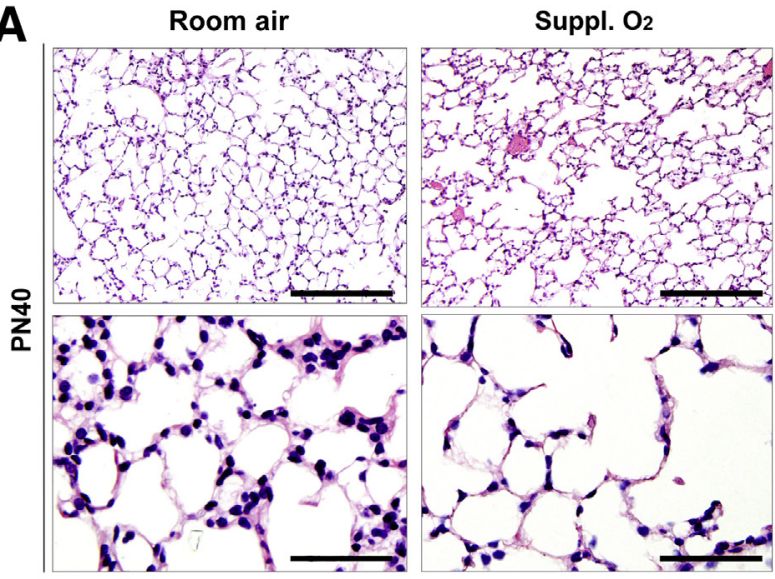

B Room air

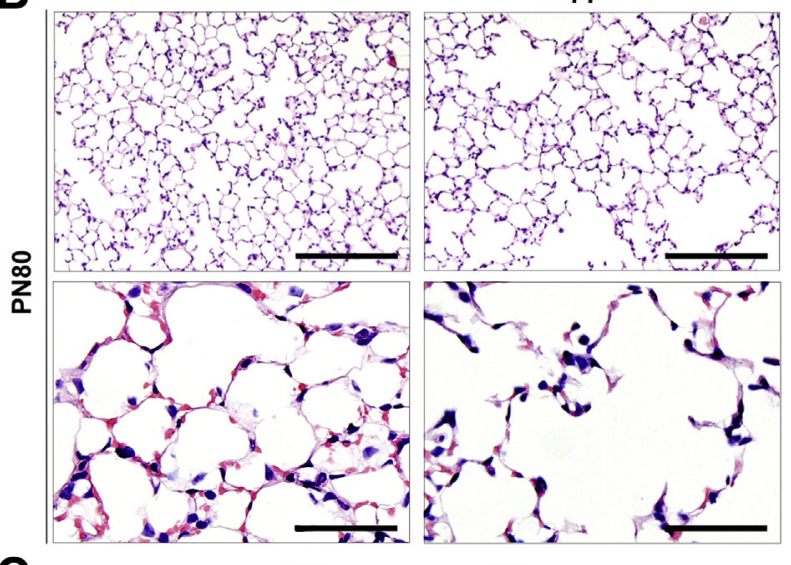

C

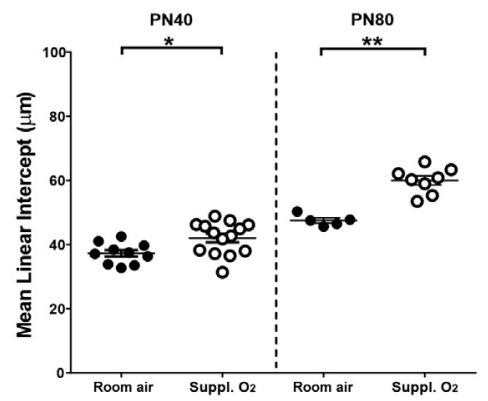

Figure 4 Emphysema develops in adult mice exposed to supplemental oxygen in infancy. A and B: Representative hematoxylin and eosin-stained lung cross-sections comparing room air and supplemental oxygen-exposed (Suppl. $0_{2}$ ) neonatal C57BL/6 mice at postnatal day (PN) 40 (A) and PN80 (B), depicting severe structural deterioration in supplemental oxygen-exposed mice. C: Morphometric quantitation of alveolar airspace size of hematoxylin and eosin-stained lung tissue sections shown in panels $\mathbf{A}$ and $\mathbf{B}$. Data are expressed as medians \pm interquartile ranges. $n=5$ to 14 mice per group. Statistical significance was determined with a nonparametric $U$-test (2-tailed). ${ }^{*} P<0.05,{ }^{*} P P<0.01$. Scale bars: 200 $\mu \mathrm{m}$ ( $\mathbf{A}$ and $\mathbf{B}$, top rows); $50 \mu \mathrm{m}$ ( $\mathbf{A}$ and $\mathbf{B}$, bottom rows). Original magnification: $\times 10$ (A and $\mathbf{B}$, top rows); $\times 40$ (A and $\mathbf{B}$, bottom rows).

\section{Discussion}

In this study, we found that early-life exposure to supplemental oxygen incites pathology, reflecting ROP and BPD in the eyes and lungs of neonatal mice, respectively, which by adulthood progresses to marked structural deformities. In addition, for the first time, we have found that factors involved in the pathogenesis of ROP, such as angiogenesis, oxidative stress, and inflammation, are similarly dysregulated in the lungs of oxygen-exposed mice. Collectively, these novel results demonstrate the existence of overlapping mechanisms causing damage to the eye and lung, providing an opportunity to use this dual disease model to manipulate these shared pathways for therapy.

During the final alveolarization phase of lung development, which is the stage that is affected in our experimental model, thinning of the alveolar air walls occurs together with microvascular maturation. ${ }^{30}$ The major structural abnormality induced by hyperoxia in neonatal lungs is thickened alveolar septal walls, which is associated with disrupted alveolar-capillary development, a key feature of human BPD. ${ }^{3}$ Changes in the epithelium are recognized to be proportional to perturbations in the underlying endothelium. ${ }^{31}$ In postmortem tissue samples from infants diagnosed with BPD, a reduced density of pulmonary arteries compared with control infants has been observed, ${ }^{32}$ which correlated with a decrease in Vegfa expression. This finding strongly suggests that changes in VEGF-A contribute to the pulmonary vascular impairment observed in BPD. ${ }^{32,33}$ Indeed, the process of alveolarization is complex and intricately timed, with factors such as VEGF-A vital for the transition of primitive alveolar saccules into functional respiratory alveolar units. ${ }^{33,34}$ In retinal development, VEGF-A is arguably the most critical factor that mediates angiogenesis and is highly sensitive to fluctuations in oxygen tension. ${ }^{35}$ Shifts in oxygen concentration cause dysregulation of VEGF-A, resulting in the pathologic remodeling of the central and peripheral regions associated with ROP, ${ }^{22-24}$ phenotypes that were recapitulated in our study. Similarly, the lung epithelium and associated microvasculature develop in close synchrony with each other, with genetic inactivation of lung epithelium-derived VEGF-A sufficient to completely suppress the formation of the underlying pulmonary capillary network. ${ }^{33,36}$ Conversely, increased VEGF-A expression can also enhance pulmonary vasculogenesis and result in disrupted branching morphogenesis of the lung, ${ }^{37}$ highlighting its precise regulation in lung. VEGFR signaling is also important in this angiogenic axis, ${ }^{38}$ and an up-regulation in Vegfr2 $(K d r)$ expression is seen in the lung during the recovery phase of the model. In response to hyperoxia, others have found that VEGF-A levels are decreased in the lung, ${ }^{34}$ which occured immediately after oxygen insult in this study. We have extended these findings by showing how this factor changes in response to differing oxygen environments, which largely parallels the biphasic expression profile of $V e g f$ reported in ROP. ${ }^{2-24}$ Therefore, these results suggest that shared pathologic angiogenic mechanisms are involved in eye and lung disorders after acute oxygen exposure.

In the eye, PDGFs are important in the activation of the angiogenesis cascade in the retina and choroid, ${ }^{39,40}$ whereas in the lung, PDGF-A, PDGF-B, PDGFR- $\alpha$, and PDGFR- $\beta$ 

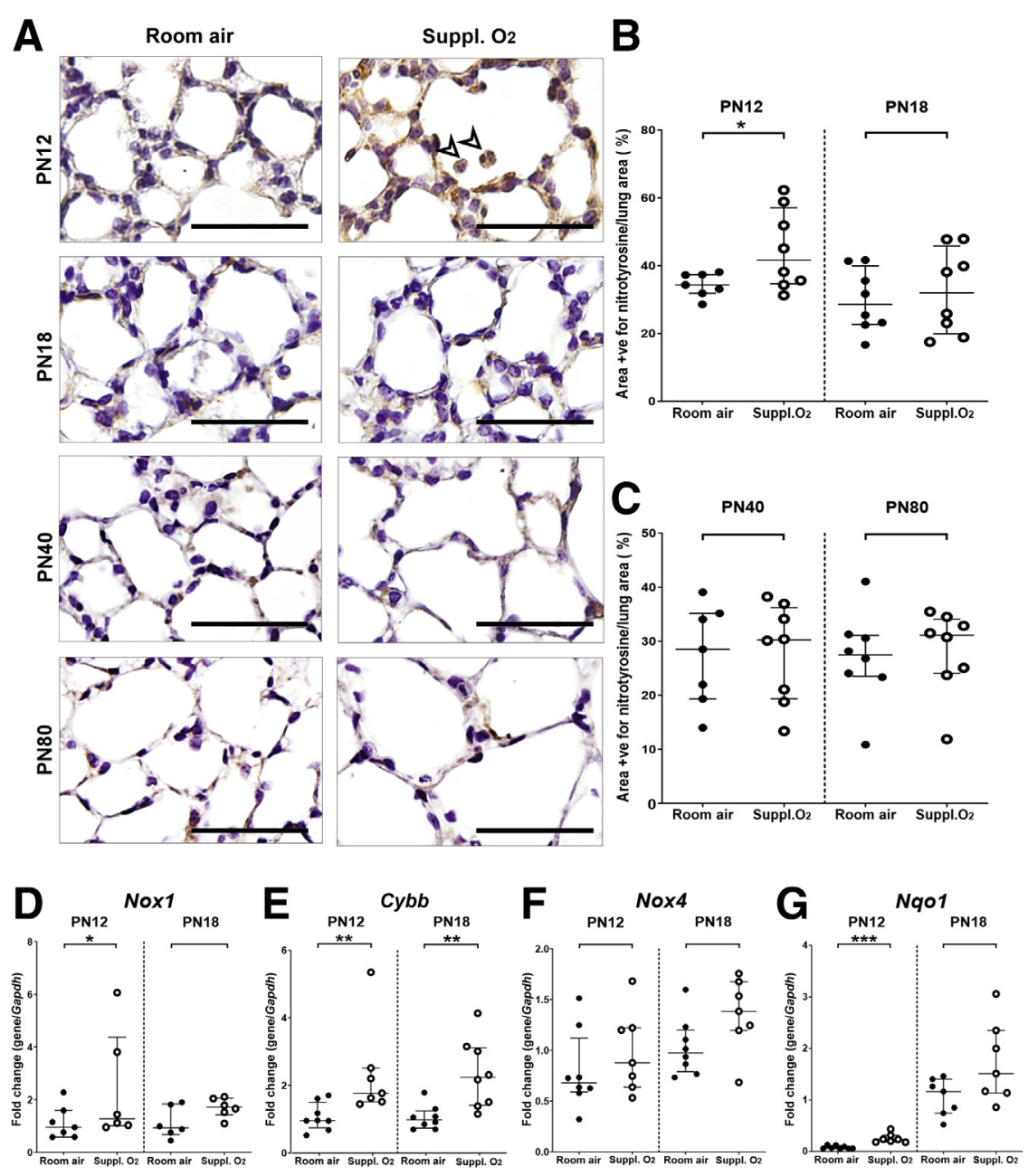

Figure 5 Elevated oxidative stress in the lungs of neonatal mice exposed to supplemental oxygen. A: Representative images of 3-nitrotyrosine (brown) immunostained lung tissue from room air or supplemental oxygen-exposed (Suppl. $0_{2}$ ) neonatal C57BL/6 mice at postnatal day (PN) 12, PN18, PN40, and PN80, with 3-nitrotyrosine-positive staining around alveoli and in alveolar macrophages (white arrowhead). B and C: Proportion of lung area stained positive for 3-nitrotyrosine per total lung tissue at PN12 and PN18 (B) and PN40 and PN80 (C). D-G: Gene expression at PN12 and PN18 of Nox1 (D), Nox2 (Cybb) (E), Nox4 (F), and Nqo1 (G) by quantitative real-time PCR of lung tissue from room air controls and supplemental oxygen -exposed mice shown in panel A. Relative change was calculated using the $2^{-\Delta \Delta C T}$ method comparing supplemental oxygen-exposed mice with room air control mice. Data are expressed as medians [relative change (gene/Gapdh)] \pm interquartile ranges. $n=7$ to 8 mice per group $(\mathbf{A}-\mathbf{C}) ; n=6$ to 8 mice per group ( $\mathbf{D}-\mathbf{G}$, mean of triplicate measurements per mouse). Statistical significance was determined with a nonparametric $U$-test (2-tailed) with outliers removed using the Grubbs test. ${ }^{*} P<0.05$, $* * P<0.01$, and $* * * P<0.001$. Scale bars $=50$ $\mu \mathrm{m}($ A). Original magnification, $\times 40($ A).

are key lung morphogenesis factors essential for the initiation of alveolar secondary septation. In this OIR model, the PDGF axis is disrupted in the lung, confirming that the injury induced by the oxygen regimen used in this model is deleterious to organs beyond the eye. Global knockout mouse studies have found that PDGF-A plays a critical role in lung myofibroblast development and alveolar septation, ${ }^{41,42}$ and lung epithelium-specific deletion of PDGF-A in mice causes enlarged alveoli that lack secondary septation and increased numbers of alveolar type II epithelial cells. ${ }^{27}$ Thus, it is not surprising that this factor was reduced in the lungs immediately after supplemental oxygen exposure. PDGF-A and PDGF-B operate in close synergy with their corresponding receptors, ${ }^{43}$ with a key study finding that $P d g f r a$ and Pdgfrb mRNA and protein expression was reduced in infant BPD lungs, as well as in the lungs of mice exposed for 14 days to $75 \%$ oxygen. ${ }^{26}$ Although a decrease in Pdgfra and Pdgfrb mRNA is also observed, this finding was not seen in the immediate post-oxygen exposure period, only at 6 days after room air recovery. We suggest this discrepancy may be attributed to differences in timing and length of oxygen exposure. Although the role of PDGF-
B in lung development is less well known, overexpression of $P d g f b$ in the developing lung can induce abnormalities as well as emphysema, inflammation, and fibrosis in the adult. $^{44}$ The current study model found sustained reduction in $P d g f b$ mRNA after supplemental oxygen exposure. Therefore, these new results indicate that acute oxygen exposure in the neonatal period used to reproduce vascular abnormalities observed in ROP, even for a brief period, can also disrupt key lung developmental pathways.

The TGF- $\beta$ family of molecules, including TGF- $\beta 1$ and its receptor TGF $\beta R 2$, are associated with fined-tuned regulation of extracellular matrix deposition and remodeling during alveolarization. ${ }^{26,45}$ Some studies have implicated this pathway in BPD because bioactive TFG- $\beta 1$ is elevated in the BAL fluid of infants with BPD, ${ }^{46,47}$ although possibly in the fibrotic response. Although the exact mechanism underpinning the involvement of the TGF- $\beta$ system in ROP have not been elucidated, limited research suggests that TGF- $\beta 1$ may contribute to pathologic blood vessel formation in the second stage of the disease because mice exposed in the OIR model showed positive staining for TGF- $\beta 1$ in regions of neovascularization in the retina. ${ }^{48}$ No consensus 


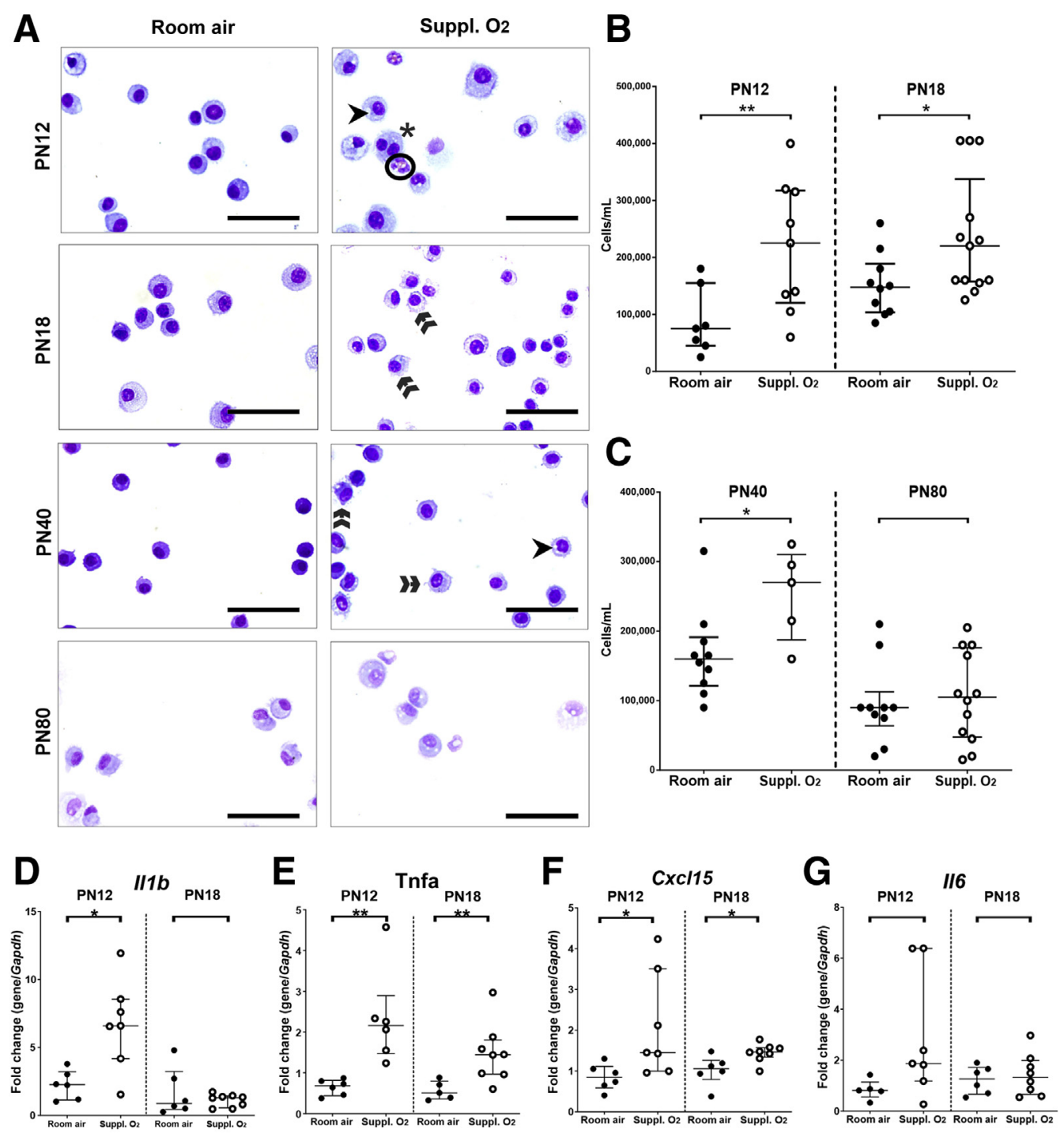

Figure 6 Inflammatory factors up-regulated in the lung after exposure of neonatal mice to supplemental oxygen. A: Cytology of immune cells extracted via bronchoalveolar lavage (BAL) from room air or supplemental oxygen-exposed (Suppl. $0_{2}$ ) neonatal C57BL/6 mice at postnatal day (PN) 12, PN18, PN40, and PN80. Although quiescent macrophages are the predominant cell type in cytospins of the room air control groups, the supplemental oxygen group at PN12 contains multinucleated macrophages (asterisk) and neutrophils (circle), and the supplemental oxygen groups from PN12 to PN80 exhibit macrophages that are larger and vacuolated (arrowheads) and contain pseudopodia projections (double arrowheads), consistent with an activated phenotype. B and C: Concentration of cells in the BAL fluid recovered from room air or supplemental oxygen-exposed neonatal mice at PN12 and PN18 (B) and PN40 and PN80 (C). D-G: Gene expression by quantitative real-time PCR of Il1b (D), Tnf $\alpha$ (Tnf) (E), CxCl15 (F), and Il6 (G) in lung tissue from room air controls and supplemental oxygen-exposed mice shown in panel A. Relative change was calculated using the $2^{-\Delta \Delta C T}$ method comparing supplemental oxygen-exposed mice with room air-exposed control mice. Data are expressed as medians (relative change [gene/Gapdh (Gapdh)]) \pm interquartile ranges. $n=5$ to 13 mice per group (B and C); $n=6$ to 8 mice per group (D-G, mean of triplicate measurements per mouse). Statistical significance was determined with a nonparametric $U$-test (2tailed) with outliers removed using the Grubbs test. ${ }^{*} P<0.05,{ }^{*} P<0.01$. Scale bars $=50 \mu \mathrm{m}(\mathbf{A})$. Original magnification, $\times 40(\mathbf{A})$.

has been established on its role in BPD because some animal model studies have found that its expression is increased in lung, ${ }^{49,50}$ whereas another study suggests it is reduced. ${ }^{51}$ Although increased expression of TGF- $\beta 1$ in neonatal rodent lung can promote BPD-like changes, ${ }^{18,52}$ the current model does not exhibit an alteration in $T g f b l$ gene expression in the lung. This finding is consistent with the lack of change in expression observed for the Tgfbr2 receptor. In a step to further understand the TGF- $\beta$ signally pathway in this model, CTGF, which is well known to bind to TGF- $\beta 1$ and activate signaling via enhancement of TGF$\beta 1$ binding to TGF $\beta R 2$, was assessed. ${ }^{53}$ CTGF has been reported to be up-regulated in animal models of BPD, ${ }^{54,55}$ although these were severe models that led to fibrosis, reminiscent of old BPD, and CTGF acts cooperatively with TGF- $\beta$ in fibrotic lung diseases. ${ }^{56}$ Again, no changes were observed in Ctgf ( $\mathrm{Ccn} 2)$ gene expression in the lung of our BPD model, in agreement with no changes observed in $T g f b 1$ or $T g f b r 2$. It is possible that TGF- $\beta$ and CTGF may fluctuate during the oxygen insult, which is not captured 
within the assessment time points. However, fibrosis was a feature of many of these aforementioned models, and TFG$\beta 1$ is recognized to play a key role in this process. The current study model did not exhibit fibrotic changes, and indeed it is a model that recapitulates new BPD, which is the prevalent form of BPD currently observed in premature neonates, which may also explain the lack of changes observed in the TGF- $\beta$ pathway in this study.

These lung-specific findings highlight the complex nature of BPD pathogenesis and how lung development is intricately regulated and can be hampered by an oxygen insult in early life. Interestingly, at the early time points, morphometric analysis of airspace diameter after oxygen insult did not reveal a significant enlargement of airspace diameter, despite showing thickened septal walls, which may relate to the age and lung maturity of the neonatal mice at the time of initial oxygen exposure. However, the alveolar structure after PN18 progressively deteriorated, suggesting that permanent and irreversible damage occurs, compromising the ability of the lung to undergo repair. ${ }^{57,58}$ It is possible that deficiency in repair is related to an exhaustion or dysregulation of resident lung stem cells, with emerging evidence of a central role for endogenous stem cell niches in regulating normal lung repair and regeneration. One such population in the lung is mesenchymal stromal cells, which orchestrate normal lung development via differentiation into lung-specific subsets. This process depends on signaling via PDGFRs and TGF- $\beta$, with the former being dysregulated in the lung tissue of oxygen-exposed mice in this model, suggesting the possibility that the resident stem cell niche within the neonatal lung is affected by the oxygen insult. Recently, a study has reported that a small population of resident airway epithelial stem cells are activated after lung injury, showing capacity to expand and differentiate into specific alveolar lineages, thereby promoting alveolar regeneration. ${ }^{59}$ Further studies of this niche are required to provide an understanding of how oxygen concentration and length of oxygen exposure impair the endogenous stem cell pool and influence the ability of the immature lung to undergo self-repair. ${ }^{60}$

Oxidative stress demonstrably contributes to lung structural damage because it manifests chronically in infants with BPD who develop chronic obstructive pulmonary disease or asthma in later life. ${ }^{61,62}$ The contribution of ROS-mediated damage in ROP has been well described, with NOX1 being a major driver of vascular injury in the retina. ${ }^{16}$ It was found that NOX1 and NOX2 are key enzymes elevated in the lung after supplemental oxygen exposure. In line with increased ROS production by NOX1, the strategic location of NOX1 on alveolar epithelial and endothelial cells ensures it can respond immediately to elevations in oxygen concentrations. ${ }^{63} \mathrm{In}$ addition, elevation in NOX2 in the lungs appears synonymous with the infiltration of leukocytes into the alveolar space after oxygen exposure because NOX2 is highly expressed on professional phagocytes and potentially on inflammationactivated endothelium. ${ }^{64}$ Strong 3-nitrotyrosine-positive staining of the lung parenchyma in the immediate post-oxygen period supports this elevation in the NOX enzymes in the lung. In comparison, the lack of transcriptional differences in Nox4 suggests that it is not involved in BPD pathogenesis.

Similar to the lung, the choroid layer of the retina is also vulnerable to long-term degeneration after acute oxygen exposure, contributed by underlying oxidative stress. ${ }^{65}$ Our finding of choroidal thinning in adult mice confirms this. In children with regressed ROP, reduced choroidal thickness has been linked to poor visual acuity, suggesting that this may be a contributor to the enduring effects of ROP on vision. ${ }^{66}$ Collectively, these findings support the activation of mutual oxidative stress pathways in both organs.

In preterm infants with BPD and ROP, the activation of macrophages and microglia, respectively, and their capacity to release proinflammatory mediators have been associated with an increased risk of developing both disorders. ${ }^{67,68}$ This finding was recapitulated in the lungs of mice exposed in the OIR model, showing an increased concentration of inflammatory cells, including vacuolated multinucleated alveolar macrophages and neutrophils, as well as elevated proinflammatory cytokines, such as $I l 1 b, T n f$, and Cxcl15. This robust inflammatory response in the initial stages of the model suggests that inflammation begins early in the lung and persists into adulthood, which could also be contributing to the long-term alveolar damage observed. Further assessment of the inflammatory profile in the lungs at later points is required to provide greater insight into the potency of the immune response in BPD-affected neonates who progress into adulthood with sustained pulmonary complications.

We have successfully developed an experimental model of coincident ROP and BPD, effectively recapitulating two human neonatal diseases. Although there has been a recent report of a similar model using rats, which complements our alveolar and retinal histologic findings, ${ }^{13}$ our study provides an in-depth analysis of the contribution of pathologic factors driving concurrent lung and eye disease through the neonatal period into adulthood. Similarities in angiogenic dysregulation, inflammation, and oxidative stress in BPD and ROP suggests that these two disorders are mechanistically linked and that a therapeutic strategy targeting shared disease pathways could simultaneously treat both diseases.

\section{Acknowledgments}

We thank the animal technicians from the precinct animal facility at the Alfred Research Alliance for animal breeding and husbandry, the Monash Histology Platform for support with histologic studies, and Suhashi M. Wickramasinghe, BSc, BOcc Therapy Hons, for manuscript review.

\section{Author Contributions}

M.L.H. conceived the study; L.C.W., J.L.W.B., and M.L.H. designed research; L.C.W., M.L., D.D., T.A.G., and E.T. performed research; L.C.W., M.L., C.J., D.T., J.L.W.B., 
E.T., and M.L.H. analyzed data; P.V.W. provided critical equipment; L.C.W. and M.L.H. wrote the manuscript; and all other authors provided editorial comment.

\section{Supplemental Data}

Supplemental material for this article can be found at https://doi.org/10.1016/j.ajpath.2020.05.016.

\section{References}

1. Johnson K, Scott SD, Fraser KD: Oxygen use for preterm infants: factors that may influence clinical decisions surrounding oxygen titration. Adv Neonatal Care 2011, 11:8-14

2. Bland RD: Neonatal chronic lung disease in the post-surfactant era. Neonatology 2005, 88:181-191

3. Hilgendorff A, O'Reilly MA: Bronchopulmonary dysplasia early changes leading to long-term consequences. Front Med 2015, 2:2

4. Vollsæter M, Røksund OD, Eide GE, Markestad T, Halvorsen T: Lung function after preterm birth: development from mid-childhood to adulthood. Thorax 2013, 68:767-776

5. Flynn JT, Bancalari E, Snyder ES, Goldberg RN, Feuer W, Cassady J, Schiffman J, Feldman HI, Baghynski B, Buckley E: A cohort study of transcutaneous oxygen tension and the incidence and severity of retinopathy of prematurity. N Engl J Med 1992, 326: 1050-1054

6. Smith L, Wesolowski E, McLellan A, Kostyk SK, D'Amato R, Sullivan R, D'Amore PA: Oxygen-induced retinopathy in the mouse. Invest Ophthalmol Vis Sci 1994, 35:101-111

7. Higgins RD, Mendelsohn AL, DeFeo MJ, Ucsel R, HendricksMunoz KD: Antenatal dexamethasone and decreased severity of retinopathy of prematurity. Arch Ophthalmol 1998, 116:601-605

8. Guven S, Bozdag S, Saner H, Cetinkaya M, Yazar AS, Erguven M: Early neonatal outcomes of volume guaranteed ventilation in preterm infants with respiratory distress syndrome. J Matern Fetal Neonatal Med 2013, 26:396-401

9. Holmström G, Broberger U, Thomassen P: Neonatal risk factors for retinopathy of prematurity-a population-based study. Acta Ophthalmol Scand 1998, 76:204-207

10. Podraza W, Michalczuk B, Jezierska K, Domek H, Kordek A, Łoniewska B, Modrzejewska M, Kot J: Correlation of retinopathy of prematurity with bronchopulmonary dysplasia. Open Med 2018, 13: $67-73$

11. Kachurina D, Sadykova AZ, Tyan E, Tulebaeva ZS, Pirmakhanova A: The bronchopulmonary dysplasia in infants with retinopathy of prematurity. Iranian J Pediatr 2014, 24:S1

12. Lange C, Ehlken C, Stahl A, Martin G, Hansen L, Agostini H: Kinetics of retinal vaso-obliteration and neovascularisation in the oxygen-induced retinopathy (OIR) mouse model. Graefes Arch Clin Exp Ophthalmol 2009, 247:1205-1211

13. Poon AWH, Ma EXH, Vadivel A, Jung S, Khoja Z, Stephens L, Thébaud B, Wintermark P: Impact of bronchopulmonary dysplasia on brain and retina. Biol Open 2016, 5:475-483

14. Klebe S, Wijngaarden Pv, Melville T, Lipsett J, Smet HD, Coster D, Williams KA: Exposure to cyclic oxygen sufficient for development of oxygen-induced retinopathy does not induce bronchopulmonary dysplasia in rats. Exp Lung Research 2010, 36:175-182

15. Connor KM, Krah NM, Dennison RJ, Aderman CM, Chen J, Guerin KI, Sapieha P, Stahl A, Willett KL, Smith LE: Quantification of oxygeninduced retinopathy in the mouse: a model of vessel loss, vessel regrowth and pathological angiogenesis. Nat Protoc 2009, 4:1565

16. Wilkinson-Berka JL, Deliyanti D, Rana I, Miller AG, Agrotis A, Armani R, Szyndralewiez C, Wingler K, Touyz RM, Cooper ME:
NADPH oxidase, NOX1, mediates vascular injury in ischemic retinopathy. Antioxid Redox Signal 2014, 20:2726-2740

17. Knudsen L, Weibel ER, Gundersen HJ, Weinstein FV, Ochs M: Assessment of air space size characteristics by intercept (chord) measurement: an accurate and efficient stereological approach. J Appl Physiol 2010, 108:412-421

18. Vicencio AG, Lee CG, Cho SJ, Eickelberg O, Chuu Y, Haddad GG, Elias JA: Conditional overexpression of bioactive transforming growth factor $-\beta 1$ in neonatal mouse lung: a new model for bronchopulmonary dysplasia? Am J Respir Cell Mol Biol 2004, 31: $650-656$

19. Pua ZJ, Stonestreet BS, Cullen A, Shahsafaei A, Sadowska GB, Sunday ME: Histochemical analyses of altered fetal lung development following single vs multiple courses of antenatal steroids. J Histochem Cytochem 2005, 53:1469-1479

20. Schindelin J, Arganda-Carreras I, Frise E, Kaynig V, Longair M, Pietzsch T, Preibisch S, Rueden C, Saalfeld S, Schmid B: Fiji: an open-source platform for biological-image analysis. Nat Methods 2012, 9:676-682

21. Duan M, Li WC, Vlahos R, Maxwell MJ, Anderson GP, Hibbs ML: Distinct macrophage subpopulations characterize acute infection an chronic inflammatory lung disease. J Immunol 2012, 189:946-955

22. Pierce EA, Foley ED, Smith LE: Regulation of vascular endothelial growth factor by oxygen in a model of retinopathy of prematurity. Arch Ophthalmol 1996, 114:1219-1228

23. Pierce EA, Avery RL, Foley ED, Aiello LP, Smith L: Vascular endothelial growth factor/vascular permeability factor expression in a mouse model of retinal neovascularization. Proc Natl Acad Sci U S A 1995, 92:905-909

24. Smith LE, Hard A-L, Hellström A: The biology of retinopathy of prematurity: how knowledge of pathogenesis guides treatment. Clin Perinatol 2013, 40:201-214

25. Hellstrom M, Lindahl P, Abramsson A, Betsholtz C: Role of PDGF-B and PDGFR-beta in recruitment of vascular smooth muscle cells and pericytes during embryonic blood vessel formation in the mouse. Development 1999, 126:3047-3055

26. Popova AP, Bentley JK, Cui TX, Richardson MN, Linn MJ, Lei J, Chen Q, Goldsmith AM, Pryhuber GS, Hershenson MB: Reduced platelet-derived growth factor receptor expression is a primary feature of human bronchopulmonary dysplasia. Am J Physiol Lung Cell Mol Physiol 2014, 307:L231-L239

27. Gouveia L, Betsholtz C, Andrae J: PDGF-A signaling is required for secondary alveolar septation and controls epithelial proliferation in the developing lung. Development 2018, 145:dev161976

28. Datta A, Kim GA, Taylor JM, Gugino SF, Farrow KN, Schumacker PT, Berkelhamer SK: Mouse lung development and NOX1 induction during hyperoxia are developmentally regulated and mitochondrial ROS dependent. Am J Physiol Lung Cell Mol Physiol 2015, 309:L369-L377

29. Wedgwood S, Steinhorn RH: Role of reactive oxygen species in neonatal pulmonary vascular disease. Antioxid Redox Signal 2014, 21:1926-1942

30. Schittny JC: Development of the lung. Cell Tissue Res 2017, 367: 427-444

31. Stenmark KR, Abman SH: Lung vascular development: implications for the pathogenesis of bronchopulmonary dysplasia. Annu Rev Physiol 2005, 67:623-661

32. Gorenflo M, Vogel M, Obladen M: Pulmonary vascular changes in bronchopulmonary dysplasia: a clinicopathologic correlation in shortand long-term survivors. Pediatr Pathol 1991, 11:851-866

33. Bhatt AJ, Pryhuber GS, Huyck H, Watkins RH, Metlay LA, Maniscalco WM: Disrupted pulmonary vasculature and decreased vascular endothelial growth factor, Flt-1, and TIE-2 in human infants dying with bronchopulmonary dysplasia. Am J Respir Crit Care Med 2001, 164:1971-1980

34. Maniscalco WM, Watkins RH, D’Angio CT, Ryan RM: Hyperoxic injury decreases alveolar epithelial cell expression of vascular 
endothelial growth factor (VEGF) in neonatal rabbit lung. Am J Respir Cell Mol Biol 1997, 16:557-567

35. Stone J, Itin A, Alon T, Pe'Er J, Gnessin H, Chan-Ling T, Keshet E: Development of retinal vasculature is mediated by hypoxia-induced vascular endothelial growth factor (VEGF) expression by neuroglia. J Neurosci 1995, 15:4738-4747

36. Yamamoto H, Yun EJ, Gerber H-P, Ferrara N, Whitsett JA, Vu TH: Epithelial-vascular cross talk mediated by VEGF-A and HGF signaling directs primary septae formation during distal lung morphogenesis. Dev Biol 2007, 308:44-53

37. Zeng X, Wert SE, Federici R, Peters KG, Whitsett JA: VEGF enhances pulmonary vasculogenesis and disrupts lung morphogenesis in vivo. Dev Dyn 1998, 211:215-227

38. Jakkula M, Le Cras TD, Gebb S, Hirth KP, Tuder RM, Voelkel NF, Abman SH: Inhibition of angiogenesis decreases alveolarization in the developing rat lung. Am J Physiol Lung Cell Mol Physiol 2000, 279:L600-L607

39. Sadiq MA, Hanout M, Sarwar S, Hassan M, Agarwal A, Sepah YJ, Do DV, Nguyen QD: Platelet-derived growth factor inhibitors: a potential therapeutic approach for ocular neovascularization. Dev Ophthalmol 2016, 55:310-316

40. Wilkinson-Berka JL, Babic S, de Gooyer T, Stitt AW, Jaworski K, Ong LG, Kelly DJ, Gilbert RE: Inhibition of platelet-derived growth factor promotes pericyte loss and angiogenesis in ischemic retinopathy. Am J Pathol 2004, 164:1263-1273

41. Bostrom H, Willetts K, Pekny M, Leveen P, Lindahl P, Hedstrand H, Pekna M, Hellstrom M, Gebre-Medhin S, Schalling M, Nilsson M, Kurland S, Tornell J, Heath JK, Betsholtz C: PDGF-A signaling is a critical event in lung alveolar myofibroblast development and alveogenesis. Cell 1996, 85:863-873

42. Lindahl P, Karlsson L, Hellstrom M, Gebre-Medhin S, Willetts K, Heath JK, Betsholtz C: Alveogenesis failure in PDGF-A-deficient mice is coupled to lack of distal spreading of alveolar smooth muscle cell progenitors during lung development. Development 1997, 124:3943-3953

43. Noskovičová N, Petřek M, Eickelberg O, Heinzelmann K: Plateletderived growth factor signaling in the lung: from lung development and disease to clinical studies. Am J Respir Cell Mol Biol 2015, 52: 263-284

44. Hoyle GW, Li J, Finkelstein JB, Eisenberg T, Liu J-Y, Lasky JA, Athas G, Morris GF, Brody AR: Emphysematous lesions, inflammation, and fibrosis in the lungs of transgenic mice overexpressing platelet-derived growth factor. Am J Pathol 1999, 154:1763-1775

45. Alejandre-Alcázar MA, Michiels-Corsten M, Vicencio AG, Reiss I, Ryu J, de Krijger RR, Haddad GG, Tibboel D, Seeger W, Eickelberg O: TGF- $\beta$ signaling is dynamically regulated during the alveolarization of rodent and human lungs. Dev Dyn 2008, 237:259-269

46. Kotecha S, Wangoo A, Silverman M, Shaw R: Increase in the concentration of transforming growth factor beta-1 in bronchoalveolar lavage fluid before development of chronic lung disease of prematurity. J Pediatr 1996, 128:464-469

47. Lecart C, Cayabyab R, Buckley S, Morrison J, Kwong K, Warburton D, Ramanathan R, Jones C, Minoo P: Bioactive transforming growth factor-beta in the lungs of extremely low birthweight neonates predicts the need for home oxygen supplementation. Neonatology 2000, 77:217-223

48. Yingchuan F, Chuntao L, Hui C, Jianbin H: Increased expression of TGF- $\beta 1$ and Smad 4 on oxygen-induced retinopathy in neonatal mice. Adv Exp Med Biol 2010, 664:71-77

49. Jin M, Lee J, Lee K-y, Jin Z, Pak JH, Kim H-S: Alteration of TGF- $\beta$ ALK-Smad signaling in hyperoxia-induced bronchopulmonary dysplasia model of newborn rats. Exp Lung Res 2016, 42:354-364

50. Luan Y, Zhang L, Chao S, Liu X, Li K, Wang Y, Zhang Z: Mesenchymal stem cells in combination with erythropoietin repair hyperoxia-induced alveoli dysplasia injury in neonatal mice via inhibition of TGF- $\beta 1$ signaling. Oncotarget 2016, 7:47082
51. Yan B, Zhong W, He Q, Zhang S, Yu J, Pan Y: Expression of transforming growth factor- $\beta 1$ in neonatal rats with hyperoxiainduced bronchopulmonary dysplasia and its relationship with lung development. Genet Mol Res 2016, 15:gmr8064

52. Gauldie J, Galt T, Bonniaud P, Robbins C, Kelly M, Warburton D: Transfer of the active form of transforming growth factor- $\beta 1$ gene to newborn rat lung induces changes consistent with bronchopulmonary dysplasia. Am J Pathol 2003, 163:2575-2584

53. Abreu JG, Ketpura NI, Reversade B, De Robertis E: Connectivetissue growth factor (CTGF) modulates cell signalling by BMP and TGF- $\beta$. Nat Cell Biol 2002, 4:599-604

54. Chen C-M, Wang L-F, Chou H-C, Lang Y-D, Lai Y-P: Up-regulation of connective tissue growth factor in hyperoxia-induced lung fibrosis. Pediatr Res 2007, 62:128-133

55. Wu S, Capasso L, Lessa A, Peng J, Kasisomayajula K, Rodriguez M, Suguihara C, Bancalari E: High tidal volume ventilation activates Smad2 and upregulates expression of connective tissue growth factor in newborn rat lung. Pediatr Res 2008, 63:245-250

56. Wang Q, Usinger W, Nichols B, Gray J, Xu L, Seeley TW, Brenner M, Guo G, Zhang W, Oliver N: Cooperative interaction of CTGF and TGF- $\beta$ in animal models of fibrotic disease. Fibrogenesis Tissue Repair 2011, 4:4

57. Londhe VA, Sundar IK, Lopez B, Maisonet TM, Yu Y, Aghai ZH, Rahman I: Hyperoxia impairs alveolar formation and induces senescence through decreased histone deacetylase activity and upregulation of p21 in neonatal mouse lung. Pediatr Res 2011, 69: $371-377$

58. Baker CD, Alvira CM: Disrupted lung development and bronchopulmonary dysplasia: opportunities for lung repair and regeneration. Curr Opin Pediatr 2014, 26:306

59. Kathiriya JJ, Brumwell AN, Jackson JR, Tang X, Chapman HA: Distinct airway epithelial stem cells hide among club cells but mobilize to promote alveolar regeneration. Cell Stem Cell 2020, 26:346-358.e4

60. Möbius MA, Thébaud B: Bronchopulmonary dysplasia: where have all the stem cells gone? origin and (potential) function of resident lung stem cells. Chest 2017, 152:1043-1052

61. Bouch S, O'Reilly M, Harding R, Sozo F: Neonatal exposure to mild hyperoxia causes persistent increases in oxidative stress and immune cells in the lungs of mice without altering lung structure. Am J Physiol Lung Cell Mol Physiol 2015, 309:L488-L496

62. Filippone M, Bonetto G, Corradi M, Frigo AC, Baraldi E: Evidence of unexpected oxidative stress in airways of adolescents born very pre-term. Eur Respir J 2012, 40:1253-1259

63. Carnesecchi S, Deffert C, Pagano A, Garrido-Urbani S, MétraillerRuchonnet I, Schappi M, Donati Y, Matthay MA, Krause K-H, Barazzone Argiroffo C: NADPH oxidase-1 plays a crucial role in hyperoxia-induced acute lung injury in mice. Am J Respir Crit Care Med 2009, 180:972-981

64. Singel KL, Segal BH: NOX2-dependent regulation of inflammation. Clin Sci (Lond) 2016, 130:479-490

65. Shao Z, Dorfman AL, Seshadri S, Djavari M, KermorvantDuchemin E, Sennlaub F, Blais M, Polosa A, Varma DR, Joyal J-S: Choroidal involution is a key component of oxygen-induced retinopathy. Invest Ophthalmol Vis Sci 2011, 52:6238-6248

66. Wu W-C, Shih C-P, Wang N-K, Lien R, Chen Y-P, Chao A-N, Chen K-J, Chen T-L, Hwang Y-S, Lai C-C: Choroidal thickness in patients with a history of retinopathy of prematurity. JAMA Ophthalmol 2013, 131:1451-1458

67. Kotecha S, Wilson L, Wangoo A, Silverman M, Shaw R: Increase in interleukin (IL)-1 $\beta$ and IL-6 in bronchoalveolar lavage fluid obtained from infants with chronic lung disease of prematurity. Pediatr Res 1996, 40:250-256

68. Deliyanti D, Talia DM, Zhu T, Maxwell MJ, Agrotis A, Jerome JR, Hargreaves EM, Gerondakis S, Hibbs ML, Mackay F: Foxp3+ Tregs are recruited to the retina to repair pathological angiogenesis. Nat Commun 2017, 8:748 